\title{
Analysis of Teacher Measurement-Evaluation Preferences from the Perspective of Epistemological Belief*
}

\author{
Ender Özeren ${ }^{1}$, Burhan Akpunar ${ }^{2}$ \\ ${ }^{1}$ Frrat University, Institute of Educational Sciences Ph. D. student, Elazığ, Turkey \\ ${ }^{2}$ Frrat University, Faculty of Education, Elazığ, Turkey \\ Correspondence: Ender Özeren, Firat University, Institute of Educational Sciences Ph. D. student, Elazığ, Turkey.
}

Received: April 22, 2019

Accepted: May 5, 2019 Online Published: May 15, 2019

doi:10.11114/jets.v7i6.4227

URL: https://doi.org/10.11114/jets.v7i6.4227

\begin{abstract}
The goal of this research is to make an epistemological analysis of methods used by high school teachers in teaching process and their measurement and evaluation preferences. The research is based on descriptive model and conducted on a total of 819 teachers. Data are collected through information form and analyzed with scientific statistical techniques. At the end of the analyses, it is observed that high school teachers participated in the research are partially sufficient in terms of epistemological belief; but these teachers stated that they highly benefit from the nature of knowledge while teaching a topic and conducting an exam. As there seems to be a dilemma between the statements and practices of teachers, the statements are found questionable. Participant teachers preferred the method of presentation in teaching process while they preferred conducting written exams in measurement-evaluation processes. These preferences justified the questionable point. This situation, which reveals the epistemological deficiency of teachers who participated in the research, is also an indication of epistemological discrepancy between current education programs and teachers. This indication shows that modern constructivist education programs in Turkey are practiced in a traditional sense. Putting education programs into practice by epistemologically destroying their nature is a serious risk that can prevent Turkey from reaching educational goals. It is known that constructivist approach makes significant contributions to ensure efficient education and to the process of raising creative individuals.
\end{abstract}

Keywords: epistemological belief, measurement and evaluation, teacher opinions, methods of teaching

\section{Introduction}

Education is considered as one of the most significant instruments in the development and progress of Turkey; the number of researches and studies on education has been increasing every day. This process is typically reflected in the change in education program in 2004-2005 academic year; the change is described as a 'reform' (Kaya and Ekiçi, 2017). The scope of this important change, which was firstly limited with the $1^{\text {st }}, 2^{\text {nd }}, 3^{\text {rd }}, 4^{\text {th }}$, and $5^{\text {th }}$ grades, is expanded in a way that it now covers all levels of education. Programs are updated with this change, and constructivist approach is put into practice; these new programs are called renewed education programs or new education programs. The programs are shaped according to cognitive and constructivist learning approaches which are based on psychology (Korkmaz, 2006); they focus on student-centered understanding. The new education programs, developed in line with the world trends, involve significant changes not only in terms of goals and contents, but also measurement and evaluation (testing practices) elements. Testing practices are fundamentally changed and renewed; purpose and function of measurement and evaluation are reconstructed (Ataman and Kabapınar, 2012). Through these changes, it is intended to remove the focus from the result of education process (product), to expand the scope and evaluate the process and product together.

As the new education program gives equal importance to the process and product, which is a doctrine of constructivist approach, it is named alternative, authentic or complementary measurement and evaluation in the literature (Sabanc1 and Yazıc1, 2017); but it is stated that the name 'alternative measurement and evaluation' doesn't properly reflect this new understanding. The understanding of complementary measurement and evaluation indicates a transition from behavioral theory to constructivist paradigm in terms of learning (Tünkler and Güven, 2018). According to this understanding, assessed and evaluated information is no longer a product; it is rather a process (Sabanci and Yazic1,

\footnotetext{
${ }^{*}$ This study is based on the doctoral thesis of the first author.
} 
2017). In terms of epistemology, "subjective" understanding of information is ahead of the "objective" understanding. Various new measurement and evaluation techniques such as rubric, project, self-measurement, portfolio, grid testing, diagnostic tree and word association have entered in Turkish education system through this transformation (Ataman and Kabapinar, 2012). It is stated that it is possible to evaluate the development of students from many aspects through complementary techniques that should be used in addition to written and verbal examinations or multiple choice exams, which are the traditional measurement and evaluation techniques. Mental developments of students are no more the single-focus of measurement and evaluation processes (Fidan and Sak, 2012).

Reaching the results expected from the above mentioned measurement and evaluation understanding depends on teachers who put the new education programs into practice in actual classrooms. It is important for them to understand and adopt the changes. This process doesn't only require knowledge, teachers should believe in the changes in programs. Teaching process can be developed and new adaptations can be properly made when there is coherence between epistemological beliefs of teachers and epistemological understanding involved in the current education programs (Carter and Norwood, 1997, Cit.: Azar, 2010: 236). Epistemological beliefs which represent the admissions about the nature and resource of knowledge, affect behaviors of teachers in classrooms (Tunca, Alkın-Şahin and Oğuz, 2015); this is why, success of new education programs, which bring important pedagogical and epistemological changes, depend on the beliefs and attitudes of teachers. Measurement and evaluation units or education programs as a whole can be useful only when teachers really appreciate and understand the positive changes targeted by these new programs.

As the topic of teacher beliefs is a broad issue, it is important to define the specific borders of this study; epistemological beliefs of teachers are the main topic of analysis in this study. In general, epistemological belief is the belief in people about how they know things and their belief in cognition (Ekinci and Tican, 2017:1748) According to Özdemir (2013: 10), who cited from different resources, epistemological beliefs is the personal and subjective beliefs of teachers about what is knowledge, what is cognition and how learning occurs. These beliefs reflect the personal views on "What is knowledge?", "How accurate is knowledge?", "How is it acquired?", "What are the limits and criteria of knowledge?" These beliefs are determinants; they have significant influence on student learning process (Kaya and Ekici, 2017). Teachers make choices while teaching a subject, evaluating how students learn (Ekinci and Tican, 2017) and deciding on some measurement and evaluation methods; all these processes are affected from their personal epistemological belief.

At this point, it is important to make correct choices that support current education programs. As the constructivist teaching programs used in Turkey since 2005 prioritize the understanding of subjective knowledge, teachers have to take teaching process and results together into consideration in measurement and evaluation processes; but in the researches carried out in Turkey, it is determined that teachers use traditional evaluation methods, they focus on the result of teaching process (Usta and Uğurlu, 2018); according to the studies in the literature, Turkish teachers have problems in process-oriented evaluations (Duban and Küçükyılmaz, 2008) and they aren't sufficient in this respect (Çoruhlu, Nas and Çepni, 2009; Anıl and Acar, 2008). Although there are various possible reasons of this insufficiency, epistemological beliefs of teachers have undoubtedly an important role. What should be discussed at that point are the reasons why Turkish teachers still use traditional measurement and evaluation techniques although modern teaching programs are put into practice in Turkey. This problem is highly important and has the potential to undermine the quality of Turkish Education System. In the Ministry of National Education's 2023 Education Vision Document, this point is emphasized; it is mentioned that "Measurement and evaluation methods shall be activated in order to increase the quality of education" (Kesen, 2019). It is highly significant for Turkey to reach education goals and current teaching programs are the basic instruments that will enable this. Teachers shall understand and put the changes made in these programs into practice not only in terms of measurement and evaluation but also as a whole (Şahin and Uysal, 2013). As student success is the main and ultimate goal of an education system (Kutlu, 2018), it is crucial to evaluate their success correctly and properly and make necessary corrections if there is any problem in the functioning of measurement or evaluation methods. It is more critical to make measurement and evaluation according to the current teaching program's epistemological paradigm. At this point, it is crucial to know the thoughts and practices of teachers about the issue; in order to have this knowledge, views of teachers about epistemological beliefs and measurement and evaluation preferences should be determined. It is expected to make contribution to the literature through this study whose goal is to make an epistemological analysis of methods and techniques used by teachers in teaching process and to understand their measurement and evaluation preferences. Although there are various studies on the issue, studies analyzing teachers' epistemological belief and measurement and evaluation preferences are limited. 


\section{Method}

\subsection{Research Model}

Survey model is used in this research. As a field of applied statistics of human research, the model is based on selecting a sample of elements from a whole environment or from a specific group and explaining a current situation (Karasar, 2005). The collected data are analyzed through content analysis. This analysis is based on presenting the obtained data in the shape of sub-themes or concepts (Koçoğlu, 2019). Information obtained from the chosen group becomes the data of the study. In survey model researches, relationships among variables are determined rather than the reasons of a case (Neuman, 2008; Karasar, 2012).

\subsection{Research Population and Sampling}

Population of the research involves teachers who were teaching in 2017-2018 academic year, fall term, in public high schools. The teachers used to work in the cities of Elazığ, Malatya, Şanlıurfa and Diyarbakır, Turkey. Research sampling, on the other hand, is made of a total of 819 teachers who accepted to answer the scale voluntarily; they represent the population properly. There are 144 teachers in Elazığ, 225 teachers in Diyarbakır, 230 teachers in Şanlıurfa and 220 teachers in Malatya. Demographic information about the sampling is presented in Table 1.

Table 1. Demographic features of teachers

\begin{tabular}{llll}
\hline Demographic Features & & $\mathbf{N}$ & $\mathbf{\%}$ \\
\hline Gender & Female & 317 & 38.7 \\
\cline { 2 - 4 } & Male & 502 & 61.3 \\
\hline \multirow{5}{*}{ Branch } & Social & 216 & 26.4 \\
\cline { 2 - 4 } & Language-Literature. & 65 & 7.9 \\
\cline { 2 - 4 } & Mathematics & 146 & 17.8 \\
\cline { 2 - 4 } & Sciences. & 120 & 14.7 \\
\cline { 2 - 4 } & Religion & 69 & 8.4 \\
\cline { 2 - 4 } & Other & 203 & 24.8 \\
\hline \multirow{5}{*}{ Seniority } & 1-5 Years & 192 & 23.4 \\
\cline { 2 - 4 } & 6-10 Years & 121 & 14.8 \\
\cline { 2 - 4 } & 11-15 Years & 114 & 13.9 \\
\cline { 2 - 4 } & 16-20 Years & 180 & 22.0 \\
\cline { 2 - 4 } & 21-25 Years & 130 & 15.9 \\
\cline { 2 - 4 } & 26-30 Years & 51 & 6.2 \\
\cline { 2 - 4 } & 31 and above & 31 & 3.8 \\
\hline \multirow{2}{*}{ Education Level } & Undergraduate & 653 & 79.7 \\
\cline { 2 - 4 } & Postgraduate & $\mathbf{8 1 9}$ & $\mathbf{1 0 0 . 0}$ \\
\hline Total & & & \\
\hline
\end{tabular}

\subsection{Data Collection Tool and Analysis of Data}

Data of the research is obtained through the Information Form developed by the researcher. There is a total of 10 items in the information form. 5 items are designed to collect personal information about teachers. The other 5 items are prepared to obtain information about the methods and techniques used by these teachers in teaching process and to determine their preferences in terms of measurement and evaluation methods. 3 of these items are about the epistemological beliefs, and graded as: "Yes, 3", "Partially, 2" and "No, 1". The remaining 2 questions are open-ended and about the methods and techniques used by teachers in teaching process and their preferences in terms of measurement and evaluation methods. After necessary permissions are taken by the researcher, the obtained data are analyzed through taking percentage, frequency and Chi-square test. $\mathrm{P}=.05$ value shows the meaningfulness level in the analyses.

\section{Findings and Interpretation}

\subsection{Findings and Interpretation of Teacher Views about Knowledge}

Participant high school teachers' views about knowledge and the reflections of their beliefs about nature of knowledge on measurement and evaluation process are presented in Table 2. 
Table 2. Teacher views about the nature of knowledge

\begin{tabular}{lllll}
\hline & & & & \\
\end{tabular}

According to Table 2, teachers find themselves partially (51.2\%) sufficient in terms of epistemology. On the basis $\mathrm{f}$ this finding, it can be said that: Epistemological sufficiency level of participant high school teacher is medium. The research result of Ekinci and Tican (2017) supports this data; the researchers determined that teachers have medium-level epistemological belief about the certainty of knowledge; they have low-level epistemological belief about inborn constant ability. Similarly, Özenç (2013) determined that classroom teachers' alternative measurement and evaluation knowledge level is medium. On the other hand, Akyıldız (2018) made a research on high school teachers and found that they have advanced epistemological belief; participant teachers mentioned that experts are the main resources of knowledge and learning is a matter of ability. Similarly, in his study, Özdemir (2013) determined that teachers have advanced belief in terms of the idea that learning depends on effort and ability, which is in line with constructivist method. Şahin and Uysal (2013) found that self-sufficiency perceptions of teacher candidates in terms of measurement and evaluation are over medium-level. Based on all these findings, it can be said that high school teachers need to feel sufficient in terms of epistemological belief in order to be able to understand and practice the current constructivist teaching programs efficiently; but the data of this research shows that they find themselves partially sufficient, which is an important deficiency.

According to table 2, participant high school teachers highly take the nature of knowledge into consideration while teaching a topic (84.9\%) and preparing questions for exam (78.9\%). This high level can be a great advantage in teaching processes and practicing the elements of measurement and evaluation of current constructivist teaching programs; but the very same teachers find themselves partially sufficient in terms of epistemology and this creates a dilemma. Teachers who think that they are not completely sufficient cannot sufficiently take the nature of knowledge into consideration. Researches on the issue (Ekinci and Tican, 2017; Bacanl1-Kurt, 2010, Karhan, 2007, Güzel, 2000, Cit: Demir and Akınoğlu, 2010) indicate that teachers in Turkey aren't completely sufficient in terms of epistemology just like the participants of our study (Çınar, 2011). As constructivist education understanding was adopted in Turkey in 2005, teachers are expected to teach topics and conduct exams according to this understanding which is based on "knowledge" (Teyfur and Teyfur, 2012) and "cognition" (Şahin, 2014). Although teachers who are partially sufficient in terms of epistemology stated that they take the nature of knowledge into consideration during their practices, this may not mean that they epistemologically take the nature of knowledge into consideration. They probably think that the nature of knowledge refers to the topics they teach in classes, namely the course contents.

According to Table 2, there is not statistically significant difference between teacher views in terms of gender, seniority and education level variables. There is significant difference in terms of branch in the $1^{\text {st }}\left[X^{2}=40.797 ; d f=10 ; p=0,000\right]$ and $2^{\text {nd }}\left[X^{2}=23.275 ; d f=10 ; p=0,010\right]$ items. According to these findings, teacher views about taking the nature of knowledge into consideration while teaching a topic or preparing questions for measurement aren't affected from the variables of gender, seniority and education level. On the other hand, there are research results in the literature indicating that teacher epistemological beliefs can vary according to some demographic features such as seniority (İçen, 2012, cit: Murat, Radmard and Yildırım, 2015) and gender (Akyıldız, 2018).

According to the research, the significant difference in the $1^{\text {st }}$ item of branch variable shows that religion class teachers find themselves the most sufficient in terms of epistemological belief $(\% 59,4 ; n=41)$; on the other hand, language teachers find themselves the least sufficient $(\% 20.0 ; n=13)$. According to this, it can be said that religion class teachers practice constructivist teaching programs and measurement and evaluation techniques of them are more constructivist when compared to other teachers. As mentioned before, teachers' epistemological beliefs are one of the most important determinants of their in-class practices. Researches about the topic show that there is a positive relation between teachers' epistemological beliefs and their constructivist learning environment preferences; these researches also indicate that teachers with advanced epistemological beliefs have bigger tendency to practice learner-centered applications (Ekinci and Tican, 2017; Özdemir, 2013). On the other hand, it is determined that language teachers find themselves less sufficient; 
this can be resulted from the high-level of awareness they have. Language teachers are expected to have more knowledge about constructivism as it is essentially a theory of language (Demir and Akınoğlu, 2010).

The significant difference in the $2^{\text {nd }}$ item of branch variable indicates that language teachers take the nature of knowledge into consideration the most (\%91.3; $\mathrm{n}=63)$, while mathematics teachers take it into consideration the least $(\% 74.0 ; \mathrm{n}=108)$. In contrast to that finding, Karalök (2014) determined that teachers graduated from Mathematics Teaching Department prefer complementary practices because of different reasons. The reason behind the fact that mathematics teachers take the nature of knowledge into consideration less than other teachers can be because they graduated from faculties other than education. In Turkey, most of the high school branch teachers are graduated from faculties (especially from the faculties of science and letters) other than Education Faculty. In the studies about adopting constructivism, it is determined that Education Faculty and Education Institutes graduate teachers have higher average scores when compared to the teachers graduated from the Faculty of Science and Letters and Engineering Faculty (Teyfur and Teyfur, 2012).

\subsection{Findings and Interpretation of Method-Technique and Measurement and Evaluation Preferences of Teachers}

Teaching methods and techniques used by the high school teachers participated in the research and their views about measurement and evaluation techniques are presented in Table 3.

Table 3. Methods-Techniques used by Teachers and Measurement and Evaluation Preferences

\begin{tabular}{|c|c|c|c|c|c|}
\hline $\begin{array}{l}\text { Teaching Methods and } \\
\text { Techniques }\end{array}$ & $\mathbf{f}$ & $\%$ & $\begin{array}{l}\text { Measurement and } \\
\text { Evaluation Techniques }\end{array}$ & $\mathbf{f}$ & $\%$ \\
\hline Presentation & 463 & 56,5 & Written exam & 463 & 56,5 \\
\hline Question- answer & 218 & 26,6 & Multiple choice tests & 219 & 26,7 \\
\hline Demonstration & 39 & 4,8 & Fill in the blanks & 70 & 8.5 \\
\hline Practice & 37 & 4,5 & Applied & 35 & 4,3 \\
\hline Brainstorming & 36 & 4,4 & True-False & 18 & 2,2 \\
\hline Discussion & 16 & 2,0 & Pairing & 7 & 0,9 \\
\hline Drama & 10 & 1,2 & Rubric-portfolio & 7 & 0,9 \\
\hline
\end{tabular}

High school teachers are required to write down the methods-techniques they use the most in teaching process and measurement and evaluation methods techniques they prefer in their exams. Findings of this process are presented in Table 3. According to the data, most of the teachers prefer covering a topic in the shape of presentation $(56.5 \%)$. Question-answer (26.6\%), demonstration (4.8\%), practice (4.5\%), brainstorming (4.4\%), discussion (2.0\%) and drama (1.2\%) are the following preferences. This finding is supported by the research data of Demirkan and Saraçoğlu (2016). The researchers determined that "high school teachers prefer narration method while teaching a topic". There are many other research results that support this finding in the literature (Y1lmaz, 2017).

According to Table 3, most of the teachers participated in the research preferred written exams (56.5\%). This is followed by multiple choice tests $(26.7 \%)$, fill in the blanks $(8.5 \%)$, practice $(4.3 \%)$, true-false test $(2.2 \%)$, pairing tests $(0.9 \%)$ and rubric/portfolio ( $0.9 \%)$. This finding is supported by the research findings of Karalök (2014). He determined that teachers prefer written exams and multiple choice tests the most. In similar researches, the obtained data indicate that teachers usually use traditional assessment methods (Gelbal and Kelecioğlu, 2007) and multiple choice question tests (Anıl and Acar, 2008; Sabanc1 and Yazıc1, 2017) to determine student success. Lack of knowledge, inability of getting used to the system, crowded classrooms, insufficiency of physical conditions and time-consuming evaluations are some of the reasons why teachers prefer traditional methods (Ataman and Karapınar, 2012). But various researches on the issue (Özenç, 2013; Erdemir, 2007, Kanatl1, 2008, Kaya, Güven, Akkuş and Günal, 2012, Cit: Pamukçu, 2015) show that the essential reason for this is insufficient knowledge level about complementary measurement and evaluation methods.

Based on all these data, it can be said that participant teachers in this research put current teaching programs, which are based on modern understanding, into practice on the basis of traditional understanding. Teaching methods and techniques, measurement and evaluation methods presented in Table 3 indicate epistemological tendencies of teachers. The table shows that teachers participated in the research don't use the modern teaching methods and techniques in current programs. In constructivist learning process, it is expected from teachers to use teaching methods and techniques such as experiment, natural observation, cooperative learning, group study, problem solving, case analysis, role play, creative drama and projects (Uşun, 2008). Similarly, in constructivist understanding, teachers are expected to use instruments such as performance assignments, observation, self-assessment, interview, rubric etc. (Öz, 2006: 39, Cit: Arslan, 2009: 147). In- service trainings organized by the Ministry of National Education can be beneficial for informing teachers; but teachers are expected to find their inadequacies and improve themselves. 
Chi-square test is used to analyze the most preferred teaching method and technique (presentation) and measurement and evaluation method (written exam) according to the variables in Table 3. At the end of the analysis, it is seen that there is significant difference in teacher preferences about presentation method in terms of the variable of branch $\left[X^{2}=133.416 ; d f=30 ; p=0,000\right]$. According to this finding, science teachers use this method the most $(65.0 \% ; n=78)$ while language teachers use this method the least $(44.6 \% ; n=29)$. As presentation is considered to be a traditional method, it can be said that high school science teachers are closer to the traditional paradigm epistemologically when compared to language teachers. Use of traditional teaching methods in high school science classes isn't acceptable in terms of constructivist paradigm; in addition to this, such practices may neglect students (Onur, 1994).

There is significant difference in teacher preferences about written exam, which is the most frequently used measurement and evaluation method, in terms of the variable of branch $\left[X^{2}=163.636 ; d f=30 ; p=0,000\right]$. According to this finding, mathematics teachers use this method the most $(75.3 \% ; \mathrm{n}=110)$ while language teachers use this method the least $(29.2 \%$; $\mathrm{n}=19$ ). This data show that high school mathematics teachers use traditional measurement and evaluation methods more than the other teachers (Taşkaya and Meydan, 2010). This preference of mathematics teachers may be resulted from the fact that they have bigger tendency to use the practices of traditional epistemology. This preference of science and mathematics teachers, which is not proper for constructivist teaching programs, may be resulted from their lack of knowledge about the methods and techniques required by this approach. Researches on the topic (Akçay, Akçay and Kurt, 2016; Fidan and Sak, 2012) support this possibility. Regardless of the cause, not using the required methods and techniques in classes and not preferring the measurement and evaluation instruments are serious deficiencies in education. According to the findings of researches in the literature, while there is a positive relationship between constructivist understanding and epistemological beliefs, there is generally a negative relationship between traditional understanding and epistemological beliefs (Akyıldız, 2018).

There is significant difference between the preferences of teachers in using written exams for measurement and evaluation in terms of the variable of gender $\left[X^{2}=140.727 ; \mathrm{df}=6 ; \mathrm{p}=0,022\right]$. According to the findings, male teachers use written exams $(58.8 \% ; n=295)$, more than female teachers $(53.0 \% ; n=168)$. This data indicates that male teachers are closer to the traditional epistemological paradigm. According to Deryakulu (2006, Cit: Çekbaş, 2015), gender and field of education shape epistemological beliefs. In various studies, it is claimed that cognitive abilities may vary according to gender (Baxter-Magolda, 1992, Cit:İenen, İlğan and Göker, 2013).

\section{Results, Discussion and Suggestions}

It is targeted to make an epistemological analysis of high school teachers in terms of the methods and techniques they use in classrooms while teaching a topic and measurement and evaluation methods they prefer. Results obtained from this research process show that high school teachers find themselves partially sufficient in terms of epistemology (Table 2); this indicates that they have medium-level epistemological belief. The very same teachers stated that they highly take the nature of knowledge into consideration while teaching a topic or making exams (Table 2). But these two statements are contradictory (Table 2) as taking the nature of knowledge into consideration, namely using constructivist learning understanding, is only possible when teachers have advanced epistemological belief (Ekinci and Tican, 2017:1749). There might be a misunderstanding at that point; participant teachers might be thinking that nature of knowledge means professional knowledge. It can be said that participant teachers are closer to the traditional understanding as they preferred presentation method (Table 3) and written exams (Table 3). Statements of teachers about taking the nature of knowledge into consideration are controversial as they have a traditional understanding about education and information. Despite the current constructivist education program which prioritizes subjective understanding of knowledge, teachers in Turkey prefer traditional measurement and evaluation approaches. As this state creates a dilemma, it can be claimed that participant teachers may have incorrect or imperfect knowledge about the nature of knowledge. This contradiction also indicates that participant teachers have the traditional epistemological paradigm, which is the opposite of constructivism (B1kmaz, 2017). On the other hand, according to Odgers's (2003) research, very few of the teachers who define themselves as mostly constructivist use this understanding in their classes (Demir and Akınoğlu, 2010). This research finding shows that there can be some other reasons behind the traditional preferences of teachers.

Partial sufficiency of participant students in terms of epistemology and their traditional preferences is a significant problem. This problem is an indicator and shows that current constructivist teaching programs, which are considered epistemologically modern, are practiced (or probably practiced) in the frame of a traditional understanding. On the other hand, another common problem in Turkey is that (Usta and Uğurlu, 2018) there is a discrepancy between current teaching programs' epistemological basis and epistemological perceptions of teachers. In fact, it is detemined that teachers in Turkey have various problems about constructivist teaching programs (Ektem, Keçici and Pilten, 2016). This problem shows that current education programs aren't properly put into practice; Turkish education system is therefore negatively affected from this deficiency. There are epistemological beliefs in the center of the practices about increasing productivity in education-training environments (Kaya and Ekiçi, 2017). According to the related researches, epistemological beliefs 
and positive attitudes make positive contributions to student centered approaches, such as constructivism, and measurement-evaluation processes (Kervan, 2017; Özdemir, 2013). It is therefore considered in the literature that teachers with high epistemological beliefs are successful (Murat, Radmard and Yıldırım, 2015); and students of these successful teachers with advanced epistemological beliefs have advanced epistemological beliefs (Brownlee, 2001, Cit: Saban and Yüce, 2012). When all these points are taken into consideration, it can be said that National Ministry of Education should primarily take necessary steps to correct epistemological deficiencies of teachers. As Turkish teachers and teacher candidates aren’t epistemologically sufficient (Koç and Memduhoğlu, 2017; Kaleci, 2012; Ekinci and Tican, 2017) the significance of this necessity is obvious.

Epistemological incompetence of high school teachers is reflected in teaching environments mostly through their preferences; they generally prefer traditional teaching methods and measurement and evaluation techniques. Because of this discrepancy between teaching programs and epistemological understanding of teachers it is not possible to reach the goals of constructivist education programs as a whole. Important points of these programs aren't properly covered and practices aren't completely understood because of this discrepancy. Because of these significant problems, Turkish education program objectives cannot be attained as planned. Constructivism targets providing students the abilities of creative and critical thinking (B1kmaz, 2017); if the content of this understanding isn't understood properly, serious problems may occur. It is highly important to involve teachers in the reforms and changes in the process of implementing constructivism. The first step that should be taken is to increase teacher qualifications in terms of epistemology as there are strong relationships between epistemological belief of teachers and learning environments (Chan \& Elliott, 2004); teaching process is shaped on the basis of the beliefs of teachers (Erdamar and Altan, 2015).

According to the findings obtained in this study, there are some crucial steps that should be taken in order to support the constructivist modern education system. Firstly, Educational institutions should organize scientific meetings about increasing epistemological beliefs of high school teachers. Secondly, teachers should be encouraged to participate actively in these meetings, congresses, symposiums etc. Finally, learning environments that enable teachers practice their epistemological beliefs should be established and supported.

\section{References}

Akçay, O. N., Akçay, A., \& Kurt, M. (2016). Investigation of the Secondary School Teachers' View and Competency to Teaching Methods and Techniques. Journal of Research in Education and Teaching, 5(1), 333-342.

Akyıldız, S. (2018). Relationships between Epistemological Beliefs and Teaching-Learning Approaches of High School Teachers. National Education, 217, 77-96.

Anıl, D., \& Acar, M. (2008). Elementary School Teachers' Views on Issues they Experience Through Measurement and Evaluation Processes . Yüzüncü Yll University, Journal of Education Faculty, V(II), 44-61.

Arslan, A. (2009). Constructivist Learning Approach and Turkish Language Teaching. Atatürk University, Journal of the Institute of Social Sciences, 13(1), 143-154.

Ataman, M., \& Kabapınar, Y. (2012). The Purpose and Efficiency of the Applications of the Assessment and Evaluation Methods in the Social Studies (4-5th Grades) Program. Amasya University, Journal of Education Faculty, 1(1), 94-114.

Azar, A. (2010). In-Service and Pre-Service Secondary Science Teachers' Self-Efficacy Beliefs about Science Teaching. ZK University, Journal of Social Sciences 6(12), 235-252.

Bıkmaz, F. (2017). Investigating the Teaching and Learning Conceptions and Scientific Epistemological Beliefs of Pre-Service Teachers: A Longtitutional Study. Education and Science 42(189), 183-196. https://doi.org/10.15390/EB.2017.4601

Çekbaş, Y. (2015). The Evaluation of the Effect of an Astronomy Course Based on Argumentation on Pre-Service Science Teachers' Nature of Science, Pseudo-Science and Epistemological Beliefs. PhD Thesis. Pamukkale University, Institute of Educational Sciences, Department of Elementary Education.

Chan, K. W., \& Elliott, R. G. (2004). Relational analysis of personal epistemology and conceptions about teaching and learning. Teaching and Teacher Education, 20 (8), 817-831. https://doi.org/10.1016/j.tate.2004.09.002

Çınar, M. (2011). Social Sciences Preservice Teachers' Views on Science and The Nature of Science M. Sc. Thesis in Curriculum and Instruction. Pamukkale University, Institute of Social Sciences, Department of Educational Sciences.

Çoruhlu, T. Ş., Nas, S., \& Çepni, S. (2009). Problems Facing Science and Technology Teachers Using Alternative Assessment Technics: Trabzon Sample. Yüzüncüyll University, Journal of Education Faculty, VI(I), 122-141. 
Demir, S., \& Akınoğlu, O. (2010). Epistemological Beliefs in Teaching Learning Processes. M. University. Atatürk Education Faculty, Journal of Educational Sciences, 32, 75-93.

Demirkan, Ö., \& Saraçoğlu, G. (2016). Views of Anatolian High School Teachers about Teaching Methods and Techniques They use in Class. The Journal of International Lingual, Social and Educational Sciences, 2(1), 1-11.

Duban, N., \& Küçükyılmaz, E. A. (2008). Primary education pre-service teachers' opinions regarding to the use of alternative measurement-evaluation methods and techniques in practice schools. Elementary Education Online, 7(3), 769-784.

Ekinci, N., \& Tican, C. (2017). Classroom Teachers' Epistemological Beliefs and Their Classroom Practices for Teaching Thinking Skills. Journal of Human and Social Sciences Researches, 6(3), 1747-1773.

Ektem, S. I., Keçici, E. S., \& Pilten, G. (2016). Views of Classroom Teachers on Process Based Measurement and Evaluation Methods. Journal of Ahi Evran University, Kırşehir Education Faculty (KEFAD), 17(3), 661-680.

Erdamar, G., \& Altan, G. (2015). Development of Epistemological Beliefs and Problem Solving Skills of Student Teachers: A Longitudinal Study. Third International Congress on Curriculum and Instruction, Çukurova University. October 22-24, 2015.

Fidan, M., \& Sak, İ. M. (2012). Primary School Teachers Opinions about Complemental Measurement And Assessment Techniques. Bartin University, Journal of Faculty of Education, 1(1), 174-189.

Gelbal, S., \& Kelecioğlu, H. (2007). Teacher' Proficiency Perceptions of about the Measurement and Evaluation Techniques and the Problems they Confront. H.U Journal of Education, 33(2007), 135-145.

Gözütok, F. D., Akgün, Ö. E., \& Karacaoğlu, Ö. C. (2005). Analysis of Primary-School Curricula in terms of Teacher Proficiency. New Primary School Curriculum Evaluation Symposium, Kayseri.

İçen, M., İlğan, A., \& Göker, H. (2013). The Analysis of Epistemological Beliefs of Nominate Social Sciences Teachers. Anatolian Journal of Educational Leadership and Instruction, 1(2), 2-11.

İflazoğlu- Saban, A., \& Güzel-Yüce, S. (2012). Problem Solving, metacognition and epistemological beliefs in 6th, $7^{\text {th }}$ and $8^{\text {th }}$ grade students. International Journal of Human Sciences, 2(9), 1402-1428.

Kaleci, F. (2012). Relationship between Pre-Service Mathematics Teachers' Epistemological Beliefs and Their Learning and Teaching Styles. Postgraduate Thesis. Necmettin Erbakan University, Institute of Education Sciences.

Karalök, S. (2014). Profiles of Middle School Mathematics Teachers Regarding Supplementary Measurement Assessment Techniques in Mathematics Course. Master Thesis. Pamukkale University, Department of Educational Sciences and Teaching

Karasar, N. (2005). Scientific Research Method. Ankara: Nobel Publications.

Karasar, N. (2012). Scientific Research Method. (23 $3^{\text {rd }}$ edition). Ankara: Nobel.

Kaya, E., \& Ekiçi, M. (2017). An Analysis of Social Studies Teachers' Epistemological Beliefs and Teaching Styles in terms of Several Variables. Elementary Education Online, 16(2), 782-813.

Kervan, S. (2017). Relationship between Teachers' Attitudes towards Multicultural Education with their Epistemological Beliefs and Teaching Approaches. PhD Thesis. Balıkesir University. Institute of Social Sciences, Department of Educational Sciences.

Kesen, İ. (2019). Measurement and Evaluation in 2023 Education Vision Document. SETA Perspective, 226, 1-6.

Kıroğlu, K. (2006). New Elementary Programs. Ankara: Pegem A Publishing. .

Koç, S., \& Memduhoğlu, H. B. (2017). Epistemological Beliefs of Preservice Teachers: A Mixed Method Study. Electronic Journal of Social Sciences, 16(60), 119-134. https://doi.org/10.17755/esosder.289655

Koçoğlu, E. (2019). Teachers' Perceptions on the Use of Social Networks in Social Studies Education. Eurasian Journal of Researches in Social and Economics, 6(3), 261-273.

Korkmaz, İ. (2006). "Evaluation of New Elementary $1^{\text {st }}$ Grade Curriculum by Teachers". Selçuk University, Journal of the Institute of Social Sciences. 16, 419-431

Kutlu, Ö. (2018). Time to Change in Measurement and Evaluation. Hürriyet, 02.04.2018.

Murat, M., Radmard, S., \& Yıldırım, G. (2015). Views of Curriculum for Primary and Secondary School Teachers. Journal of Research in Education and Teaching, 4(4), 312-322.

Neuman, W. L. (2008). Social Research methods ( $3^{\text {rd }}$ edition). (Trans. by S.Özge.). Ístanbul: Yayınodası Publications 
Onur, B. (1994). Psychology and Pathology of Migration and Culture Transformation, Turkish-Deutsch Psychiatry Congress, April 16-24, 1994 Antalya.

Özdemir, İ. (2013). Relationship between Elementary School Teachers' Epistemological Beliefs and Their Attitude towards Constructivist Approach, Master of Science Thesis. Pamukkale University, Department of Educational Sciences.

Özenç, M. (2013 Determination of Levels of Primary School Teachers' Alternative Assessment and Evaluation Knowledge. Dicle University, Journal of Ziya Gökalp Education Faculty, 21, 157-178

Pamukçu, C. (2015). The Effect of Complementary Assessment and Evaluation Development Curriculum on the Knowledge Level of Geography Pre-Service Teachers. PhD Thesis. Necmettin Erbakan University, Institute of Educational Sciences.

Sabanc1, O., \& Yazıcı, K. (2017). Examining Pre-service Teachers' Efficacy Perceptions towards Measurement and Evaluation. Trakya University, Journal of Education Department, 7(1), 128-153. Şahin and Uysal, 2013

Şahin, H. (2014). The Reflections of the Constructivist Approach to Science Teaching. Mehmet Akif Ersoy University, Journal of Education Faculty, 29, 151-170.

Taşkaya, S. M., \& Meydan, A. (2010). An investigation on Assessment Tools Applied in Main Scientific Branch Primary School's Teaching. $2^{\text {nd }}$ International Congress of Assessment and Evalution in Education and Psychology. May, 5-7, 2010, Mersin.

Tekışık, H. H. (2005). Preparation of Teachers for the Practice of New Elementary Education Curricula, New Primary School Curriculum Evaluation Symposium, Kayseri. Erciyes University, October, 14-16, Kayseri, 11-15.

Teyfur, M., \& Teyfur, E. (2012). Investigation of School Administrators' Views Regarding the Constructivist Curricula (İzmir City Sample). Adnan Menderes University, Journal of Educational Sciences, 3(2), 66-81.

Tunca, N., Alkın-Şahin, S., \& Oğuz, A. (2015). The Relationship between Teachers' Educational Beliefs and Professional Values. Kalem Education and Human Sciences Journal, 5(1), 11-47. https://doi.org/10.23863/kalem.2017.43

Tünkler, V., \& Güven, C. (2018). The Effect of Microteaching Practice on Preservice Teachers' Literacy Levels Concerning Complementary Assessment and Evaluation Techniques. H. U. Journal of Education, 1-24. https://doi.org/10.16986/HUJE.2018043466

Usta, H. G., \& Uğurlu, C. T. (2018). The Use and Supervision of Intraclass Measurement and Evaluation Methods: The Views of Supervisor and Teacher. Electronic Journal of Social Sciences, 17(67), 969-981. https://doi.org/10.17755/esosder.332783

Uşun, S. (2008). Analysis of Methods and Techniques used in Constructivist Teaching Programs in terms of Constructivist Learning Theory Principals. $2^{\text {nd }}$ International Computer and Instructional Technologies Symposium, April, 16-18, 2008, İzmir.

Yangin, B. (2005). Evaluation of Primary Education Turkish Curriculum and the Guidebook, Educational Sciences in Theory and Practice, 5(2), 477-516.

Y1lmaz, Ö. (2017). Instructional Strategies, Methods and Techniques Preferred By Science Teachers: Thoughts of Science Teacher Candidates. Ĭgdır University, Journal of Social Sciences, 12, 493-510.

\section{Copyrights}

Copyright for this article is retained by the author(s), with first publication rights granted to the journal.

This is an open-access article distributed under the terms and conditions of the Creative Commons Attribution license which permits unrestricted use, distribution, and reproduction in any medium, provided the original work is properly cited. 